\section{Interleukin-1 receptor inhibition reduces stroke size in a murine model of sickle cell disease}

\author{
Jessica Venugopal, ${ }^{1}$ Jintao Wang, ${ }^{1}$ Jalal Mawri, ${ }^{2}$ Chiao Guo ${ }^{1}$ and \\ Daniel T. Eitzman ${ }^{1}$
}

${ }^{1}$ University of Michigan Internal Medicine - Cardiology Division and ${ }^{2}$ University of Michigan, Ann Arbor, MI, USA

\section{ABSTRACT}

S ickle cell disease (SCD) is associated with chronic hemolytic anemia and a heightened inflammatory state. The causal role of inflammatory pathways in stroke associated with SCD is unclear. Therefore, the hypothesis that deletion of the non-hematopoietic interleukin-1 receptor (IL-1R) pool may be beneficial in SCD was pursued. Since potential deleterious effects of IL-1R signaling in SCD could be mediated via downstream production of interleukin- 6 (IL-6), the role of the nonhematopoietic IL-6 pool was also addressed. Bone marrow transplantation (BMT) from SCD to wild-type (WT) recipient mice was used to generate SCD mice $\left(W t, \mathrm{SCD}^{\mathrm{bm} t}\right)$. In order to generate mice with nonhematopoietic deficiency of IL-1R or IL- 6 , SCD marrow was transplanted into IL-1R deficient (IL1 $\left.R^{-/-}, \mathrm{SCD}^{\mathrm{bmt}}\right)$ or IL-6 deficient recipients $\left(I L 6^{-/}\right.$, $\mathrm{SCD}^{\text {bmt }}$ ). Blood counts, reticulocytes, soluble E-selectin (sEsel), and IL-6 levels were analyzed 14-15 weeks post-BMT. Ischemic stroke was induced by middle cerebral artery (MCA) photothrombosis at 16 weeks post-BMT. A separate group of $W t, \mathrm{SCD}^{\mathrm{bmt}}$ mice was given the IL-1R inhibitor, anakinra, following stroke induction. Seventy-two hours after MCA occlusion, stroke volume was assessed by staining brain sections with 2,3,5-triphenyltetrazolium chloride. Formalin-fixed brain sections were also stained for macrophages with MAC3, for endothelial activation with ICAM-1, and for loss of blood brain barrier integrity with fibrin(ogen) staining. All SCD mice generated by BMT were anemic and the severity of anemia was not different between $W_{t}, \mathrm{SCD}^{\mathrm{bmt}}$, $I L 1 R^{-1-}, \mathrm{SCD}^{\mathrm{bmt}}$, and $I L-6^{-1-}, \mathrm{SCD}^{\mathrm{bmt}}$ mice. Three days following MCA occlusion, stroke volume was significantly reduced in $I L 1 R^{--}, \mathrm{SCD}^{\mathrm{bmt}}$ mice compared to $\mathrm{Wt}, \mathrm{SCD}{ }^{\mathrm{bmt}}$ mice and $I L 6^{-1 /}, \mathrm{SCD}^{\mathrm{bmt}}$ mice. Plasma levels of sEsel were lower in $I L 1 R^{-/}, \mathrm{SCD}^{\mathrm{bmt}}$ compared to $\mathrm{Wt}, \mathrm{SCD}{ }^{\mathrm{bmt}}$ and $I L-6^{-1-}, \mathrm{SCD}^{\mathrm{bmt}}$ mice. Post-stroke treatment of $\mathrm{Wt}_{\mathrm{t}} \mathrm{SCD}^{\mathrm{bmt}}$ mice with anakinra decreased stroke size, leukocyte infiltration, ICAM-1 expression, and fibrin(ogen) accumulation compared to vehicle-treated mice. Deficiency of non-hematopoietic IL-1R or treatment with an IL-1R antagonist is sufficient to confer protection against the increased stroke size associated with SCD. These effects of IL1R deficiency are associated with reduced endothelial activation, leukocyte infiltration, and blood brain barrier disruption, and are independent of non-hematopoietic IL-6 signaling.

\section{Introduction}

Sickle cell disease (SCD) is associated with acute and chronic vascular complications leading to premature morbidity and mortality, including adverse cerebrovascular events, such as stroke. ${ }^{1}$ The stroke risk for a child with SCD is over 300 times greater than for a child without SCD2 with clinically apparent strokes occurring in $11 \%$ of SCD patients before the age of 20 . Approximately two thirds of these patients experience recurrent cerebral infarction. ${ }^{3}$ Genotype greatly influences the
Haematologica 2021

Volume 106(9):2469-2477

\section{Correspondence:}

DANIEL T. EITZMAN

deitzman@umich.edu

Received: March 10, 2020.

Accepted: August 5, 2020.

Pre-published: August 13, 2020.

https://doi.org/10.3324/haematol.2020.252395

(C)2021 Ferrata Storti Foundation

Material published in Haematologica is covered by copyright. All rights are reserved to the Ferrata Storti Foundation. Use of published material is allowed under the following terms and conditions:

https://creativecommons.org/licenses/by-nc/4.0/legalcode. Copies of published material are allowed for personal or internal use. Sharing published material for non-commercial purposes is subject to the following conditions: https://creativecommons.org/licenses/by-nc/4.0/legalcode, sect. 3. Reproducing and sharing published material for commercial purposes is not allowed without permission in writing from the publisher. 
risk of stroke in SCD patients, with those with hemoglobin $(\mathrm{Hb}) \mathrm{SS}$ having the highest risk and those with sickle $\beta^{+}$-thalassemia having the lowest risk. ${ }^{2}$ In general, the most prevalent subtype of stroke associated with SCD patients is ischemic stroke, however between the ages of 20 and 29 hemorrhagic strokes are more prevalent. ${ }^{2}$ Stroke prevention in SCD patients is primarily accomplished through chronic blood transfusions ${ }^{4}$ and hydroxyurea treatment. $^{5-7}$

Although erythrocyte sickling in response to stressors constitutes the primary underlying defect of SCD, subsequent inflammatory responses to vascular occlusive events contribute to organ damage and further vascular dysfunction..$^{8-11}$ This heightened inflammatory milieu is characterized by leukocytosis and elevated levels of cytokines in SCD. ${ }^{12-14}$ Therapies shown to be beneficial in SCD such as hydroxyurea and anti-selectin antibodies may exert their beneficial effects, in part, via dampening of leukocyte-mediated inflammatory responses. ${ }^{15,16}$

Hemolysis in SCD may result in the activation of leukocytes via Toll-like receptors (TLR) and NOD-like receptor 3 (NLRP3) by free heme. ${ }^{17}$ TLR and NLRP3 inflammasome expression levels, including interleukin-1 $\beta$ (IL-1 $\beta$ ), are increased in peripheral blood monocytes from SCD patients. ${ }^{18,19} \mathrm{IL}-1 \beta$ is a particularly important mediator of acute and chronic inflammatory disease processes, as therapeutic targeting of IL-1 $\beta$ has proven beneficial in several inflammatory diseases. ${ }^{20-22}$ Additionally, some genetic polymorphisms of IL-1 $\beta$ have been shown to affect IL-1 $\beta$ transcription and are associated with arthritis, cardiovascular disease, and complications of SCD. ${ }^{9,23,24}$ While these studies suggest IL-1 $\beta$ signaling pathways are involved in some manifestations of SCD, the causal role of these pathways remains unclear.

IL-1 $\beta$ may represent a particularly important modulator of stroke outcomes. ${ }^{25,26} \mathrm{IL}-1 \beta$ is rapidly upregulated during ischemic stroke and may contribute to ischemic injury. ${ }^{26}$ In a meta-analysis of 16 non-SCD animal studies, administration of the IL-1R antagonist, anakinra, produced a $36 \%$ reduction of infarct volume. ${ }^{27}$ IL-1 $\beta$ may promote neuronal death indirectly, via effects on astrocytes and endothelial cells. ${ }^{25}$ The binding of IL-1 $\beta$ to astrocyte IL-1R activates signaling cascades resulting in the production of IL-6, TNF- $\alpha$, and other chemokines which influence central nervous system (CNS) inflammation ${ }^{28}$ and neurotoxicity. ${ }^{28}$ Neurotoxicity mediated by IL-1 $\beta$ may also occur through endothelial interleukin-1 receptor (IL-1R)-mediated activation of cerebral endothelial cells, ${ }^{30}$ leading to leukocyte infiltration ${ }^{31}$ and the loss of blood brain barrier integrity. ${ }^{32}$ The recruitment of peripheral leukocytes by IL-1 $\beta$ can sustain neuroinflammation, ${ }^{33}$ further promoting neurotoxicity, ${ }^{34}$ and blood brain barrier (BBB) disruption. ${ }^{35}$ IL-1 $\beta$ may also induce permeability of the $\mathrm{BBB}$ directly through endothelial cell signaling pathways. ${ }^{36}$

Mouse models of SCD have been developed that mimic the predominant features of SCD in humans..$^{37-39}$ In gener$\mathrm{al}$, these mice exhibit hemolysis, anemia, splenomegaly, and multi-organ infarcts. ${ }^{37-39}$ SCD mice have thus been a useful aid to identify mechanisms involved in vaso-occlusion and to test potential therapeutic interventions. Because of reduced fertility and complex genetics, generating SCD mice with complete deficiency of a diseasemodifying candidate gene through intercrosses is cumbersome, as is generation of suitable littermate controls. However, bone marrow transplantation (BMT) is an effi- cient means to generate SCD mice, and if a candidate gene of interest exerts its effects via non-bone marrow-derived cellular pools, then informative SCD mice can be readily generated by transplanting SCD marrow to recipient mice with deficiency of the candidate gene. In order to modify IL-1 $\beta$ signaling pathways using this strategy, transplantation of SCD marrow to mice lacking the receptor for IL-1 $\beta$, (IL-1R), leads to lack of IL-1 signaling in nonhematopoietic IL-1R cellular pools. The endothelial IL-1R pool is responsible for mediating the upregulation of endothelial adhesion molecules and leukocyte-endothelial interactions in response to IL-1 $\beta$ stimulation, ${ }^{40}$ which might be particularly relevant to SCD pathogenesis. Therefore, to study IL-1 $\beta$ signaling pathways in SCD, mice were generated by transplanting SCD marrow into recipients with IL-1R deficiency and compared to control wild-type (WT) recipients on the same C57BL6/J strain background. The role of IL-1R signaling was then analyzed with regards to anemia and stroke in SCD mice. The effect of an IL-1R pharmacologic antagonist was also assessed.

\section{Methods}

\section{Animals}

Male C57BL/6 wild-type (WT), homozygous SCD ( SCD, Stock No:013071 Townes model), IL1R null mice (IL1R ${ }^{-r}$, Stock No: 003245), interleukin-6 null mice (IL6 $\%$, Stock No: 002650) were purchased from Jackson Laboratory (Bar Harbor, Maine, USA). SCD and control experimental mice were then generated by BMT from SCD mice into $W T, I L 1 R^{-/}$, and $I L 6^{-/}$recipients. Additional controls were generated by transplantation of WT marrow into WT recipients. Mice were housed under specific pathogen-free conditions in static microisolator cages with tap water ad libitum in a temperature-controlled room with a 12:12-hour light/dark cycle. Mice were fed a standard laboratory rodent diet (No. 5001 TestDiet, Richmond, IN, USA). All animal use protocols complied with the Principle of Laboratory and Animal Care established by the National Society for Medical Research and were approved by the University of Michigan Committee on Use and Care of Animals.

\section{Bone marrow transplantation and blood parameter analysis}

SCD mice were generated by BMT as previously described. ${ }^{41,42}$ Briefly, 8 week-old male WT, IL1 $R^{-1-}$ and $I L 6^{-1}$ mice were used as recipients that received bone marrow from 8 week-old SCD male donors. Bone marrow was harvested from the donor mice by flushing their femurs and tibias with RPMI medium (Gibco/Invitrogen, Carlsbad, CA, USA) containing 10\% fetal bovine serum (Gibco/Invitrogen, Carlsbad, CA, USA). Cells were then centrifuged at $300 \mathrm{~g}$ and resuspended in phosphate-buffered saline before injection. Each recipient mouse was irradiated $(2 \times 650 \mathrm{rad}[0.02 \times 6.5 \mathrm{~Gy}])$ and injected with $4 \times 10^{6}$ bone marrow cells via the tail vein in a $200 \mu \mathrm{L}$ bone marrow suspension in phosphate-buffered saline. Acid water $(6 \mathrm{mM} \mathrm{HCl}, \mathrm{pH}=2.5)$ was provided to animals beginning 4 days before BMT to 4 weeks following BMT. Transplant efficiency was determined by hemoglobin electrophoresis, as done previously. ${ }^{41,43,15}$ weeks following BMT, blood parameter analyses were performed with a Hemavet (Drew Scientific, Inc) on whole blood collected in EDTA-lined tubes via retro-orbital sampling from isofluorane-anesthetized mice $(\mathrm{n}=5$ per group). Reticulocyte percentages were quantified by new methylene blue staining ( $\mathrm{n}=5$ per group) (Ricca Chemical 
Company, Arlington, TX, USA), according to the manufacturer's instructions and expressed as a percentage of total erythrocytes.

\section{Stroke model}

Sixteen weeks after BMT, middle cerebral artery (MCA) occlusion was induced by photochemical injury as previously described, ${ }^{41,42} \mathrm{n}=3-5$. On day 3 following MCA occlusion, mice were anesthetized with pentobarbital, and blood drawn via cardiac puncture. Mouse bodies were perfused with PBS, then brains were excised and sliced into $2 \mathrm{~mm}$ segments before staining for 20 minutes with 2, 3, 5-triphenyltetrazolium chloride at room temperature while protected from light. The brain sections were imaged with a Nikon SMZ-2T microscope and Spot Idea camera model 29.2-13MP using Spot 5.1 software, and stroke size was then calculated as done previously. ${ }^{41}$ Brain macrophages were stained with an anti-mouse MAC3 antibody (1:200; \#550292, BD Biosciences, San Jose, CA), n=3-5. Fibrin(ogen) was stained with an anti-mouse fibrin(ogen) antibody (1:4,000; ab189490, Abcam, Cambridge, MA) and ICAM-1 was stained with anti-mouse ICAM-1 antibody (2 ug/mL; \#14-0542-85, ThermoFisher Scientific, Waltham, MA), followed by a biotin-conjugated secondary IgG (1:100), n=3-5. A Nikon Microphot-SA Epi-FL3 microscope, Nikon Ds Fi3 camera, and NIS Elements software were used to capture images. Quantification of fibrin(ogen) stained area was performed with Image J software. Quantification of MAC3positive cells was attained for each mouse by manually counting stained cells in 20 fields of view at 10x. For each field, the number of MAC3-positive cells was divided by the area of brain imaged in each field.

\section{Circulating E-selectin and IL-6 measurements}

Soluble E-selectin (sEsel), and IL-6 enzyme-linked immunosorbent assays (ELISA) were performed according to the manufacturer's instructions ( $\& \& D$ Systems, Inc.; Minneapolis MN, USA; Cat\#: MES00 \& MPS00), n=3-5. Blood for ELISA was collected via cardiac puncture at the time of sacrifice and plasma prepared by centrifugation at $8,500 \mathrm{rpm}$ for $10 \mathrm{~min}$.

\section{Drug treatment}

Anakinra (Swedish Orphan Biovitrum AB, Stockholm, Sweden) $(100 \mathrm{mg} / \mathrm{kg}$ via one intraperitoneal injection [i.p.]) or vehicle control (phosphate buffered saline) was administered 1 hour following induction of stroke ( $\mathrm{n}=4$ per group).

\section{Statistical analysis}

Data are presented as mean \pm standard deviation. Analysis was carried out using GraphPad Prism and tests for normality were performed using the Shapiro-Wilk test. Differences between groups were then analyzed using a one way ANOVA or an unpaired $t$-test for comparison between groups or Mann Whitney $\mathrm{U}$ test. Probability values of $P<0.05$ were considered statistically significant.

\section{Data sharing}

For original data, please contactdeitzman@umich.edu.

\section{Results}

\section{Effect of IL-1R and IL-6 status on hematological data in SCD mice}

In order to determine whether signaling through the IL$1 \mathrm{R}$ or IL-6 in non-hematopoietic tissues would impact anemia in SCD mice, whole blood was analyzed for cell counts, platelets, and reticulocytes 15 weeks following
BMT. Compared to WT mice transplanted with WT bone marrow (Wt,WT ${ }^{\text {bmt }}$ ), WT recipients of SCD bone marrow $\left(W t, \mathrm{SCD}^{\mathrm{bm} t}\right)$ were more anemic with elevated leukocyte and reticulocyte counts (Figure 1). $I L-1 R^{-/}$and $I L-6^{-/}$recipients of SCD marrow $\left(I L 1 R^{-1}, S^{\prime} C D^{\text {bmt }}\right.$ and $I L 6^{-1}, S^{-6} D^{\text {bmt }}$ ) displayed similar anemia and reticulocyte counts compared to $W t, \mathrm{SCD}^{\mathrm{bmt}}$ mice (Figure 1).

\section{Effect of IL-1R and IL-6 status on circulating levels of IL- 6 in SCD mice}

Plasma levels of IL-6 were detectable in $W t, \mathrm{SCD}^{\text {bmt }}$ mice $(4.877 \pm 3.62 \mathrm{pg} / \mathrm{mL})$ but undetectable in both $I L-1 R^{-1}, \mathrm{SCD}^{\mathrm{bmt}}$ and $I L 6^{-1}, \mathrm{SCD}^{\mathrm{bmt}}$ mice, consistent with a non-hematopoietic source for circulating IL-6 in SCD and a critical role for non-hematopoietic IL-1 receptor signaling towards IL-6 levels in SCD.

\section{Effect of IL-1R and IL-6 status on stroke size in sickle cell disease following middle cerebral artery occlusion}

SCD mice have been shown to experience larger strokes following MCA occlusion due to vasocclusion by sickled erythrocytes in the penumbra. ${ }^{42}$ In order to determine whether IL1 $R^{-1}, \mathrm{SCD}^{\mathrm{bmt}}$ mice would be protected from the increased stroke size associated with SCD, photochemicalmediated thrombosis was induced in the MCA in $\mathrm{Wt}, \mathrm{SCD}^{\mathrm{bmt}}$ mice and $I L-1 R^{-1}, \mathrm{SCD}^{\mathrm{bmt}}$ mice. Three days later, the stroke area was quantitated and $I L-1 R^{-1}, \mathrm{SCD}^{\text {bmt }}$ mice were found to have a similar stroke areas to $\mathrm{Wt}, \mathrm{WT}^{\mathrm{bmt}}$ mice, both of which had reduced areas when compared to $W t, \mathrm{SCD}^{\mathrm{bmt}}$ mice (Figure $2 \mathrm{~A}$ to $\mathrm{C}$ ). In contrast, stroke size in $I_{L} 6^{-1}, S_{C D}{ }^{\text {bmt }}$ mice was not reduced compared to $W t, S C D^{\text {bmt }}$ mice (Figure 2D). Thus, although non-hematopoietic IL-1R signaling pathways regulate circulating IL-6 levels, this pathway does not account for the effects of nonhematopoietic IL-1R signaling on stroke size in SCD.

Reduction in stroke size in $I L-1 R^{-1}, \mathrm{SCD}^{\mathrm{bmt}}$ mice was also associated with reduced peri-infarct infiltration of macrophages, as denoted by staining of MAC3 (Figure 3). Since endothelial IL-1R signaling regulates expression of endothelial adhesion molecules ${ }^{40,44}$ which could affect the stroke phenotype, levels of sEsel were measured given its endothelial specificity. Plasma levels of sEsel were found to be significantly reduced in $I L-1 R^{-/,}, \mathrm{SCD}^{\mathrm{bmt}}$ compared to $W t, \mathrm{SCD}^{\mathrm{bmt}}$ mice $(32.12 \pm 2.08 \mathrm{ng} / \mathrm{mL}$ vs. $50.10 \pm 2.31 \mathrm{ng} / \mathrm{mL}$; $P=0.03)$. Circulating values of sEsel in $I L 6^{-1-}, \mathrm{SCD}^{\text {bmt }}$ were not significantly different compared to $W t, \mathrm{SCD}^{\mathrm{bmt}}(54.03 \pm 10.10$ $\mathrm{ng} / \mathrm{mL}, P=0.37)$. Fixed brain sections were also stained for ICAM-1. Expression of ICAM-1 was significantly decreased $I L-1 R^{-1-}, \mathrm{SCD}^{\mathrm{bmt}}$ compared to $W t, \mathrm{SCD}^{\mathrm{bmt}}$ mice $(0.008 \pm 0.002 \%$ area vs. $0.029 \pm 0.007 \%$ area, $P<0.05)$.

Increased infiltration of leukocytes may diminish blood brain barrier integrity, leading to leakage of fibrin(ogen)containing plasma into the brain from the vasculature. ${ }^{45-47}$ Fibrin(ogen) immunopositivity was significantly decreased in $I L-1 R^{-\prime}, \mathrm{SCD}^{\mathrm{bmt}}$ compared to $W t, \mathrm{SCD}^{\mathrm{bmt}}$ mice, whereas $I L 6^{-1}, \mathrm{SCD}^{\mathrm{bmt}}$ were not significantly different than $W t, \mathrm{SCD}^{\mathrm{bmt}}$ mice (Figure 4).

\section{Effect of single dose anakinra on stroke size given post middle cerebral artery occlusion}

From a practical therapeutic standpoint, treatment with antagonists of IL-1 $\beta$ or IL-1 receptor signaling pathways may not be feasible in SCD patients prior to the onset of stroke, however therapies could be administered following 
stroke onset. In order to determine whether stroke size could be reduced by pharmacologic blockade of the IL-1R, even when administered following MCA occlusion, the IL$1 \mathrm{R}$ antagonist, anakinra, was administered 1 hour following stroke induction in $W t, \mathrm{SCD}^{\mathrm{bmt}}$ mice. Compared to vehicle control, mice given anakinra after stroke onset experienced reduction in stroke volume when analyzed 3 days following MCA occlusion (Figure 5). A decrease in peri-infarct MAC3-positive cells was also observed (Figure 6), similar to what was seen in $I L 1 R^{-/}, \mathrm{SCD}^{\mathrm{bmt}}$ brain sections post-stroke.

\section{Discussion}

SCD results from a missense mutation leading to an amino acid substitution in the $\beta$-globin gene. ${ }^{48}$ Although SCD is a monogenic disease, there is marked phenotypic heterogeneity in patients with SCD that applies to anemia, cerebrovascular disease, acute chest syndrome, pain crises, and death. ${ }^{49,50}$ Differential activation of inflammatory pathways may be a mechanism which accounts for the observed phenotypic heterogeneity and may be a critical link between hemolysis and subsequent vascular complications. ${ }^{10}$ Multiple cytokines, including IL- $1 \beta$ and IL- 6 , have been postulated to play a role in SCD phenotypes, and as these cytokines are also known to regulate stroke volume in non-SCD populations, the hypothesis that the deletion of the endothelial IL-1R pool may be beneficial in SCD was pursued by utilizing an MCA occlusion model. This model of stroke leads to sustained occlusion of the MCA in the absence of treatment $t^{51}$ and the increased stroke size in sickle cell mice is likely due to vaso-occlusion in the penumbra microvasculature. ${ }^{42}$ Since potential deleterious effects of IL$1 \mathrm{R}$ signaling in SCD could be mediated via downstream production of IL-6, this pathway was also studied.
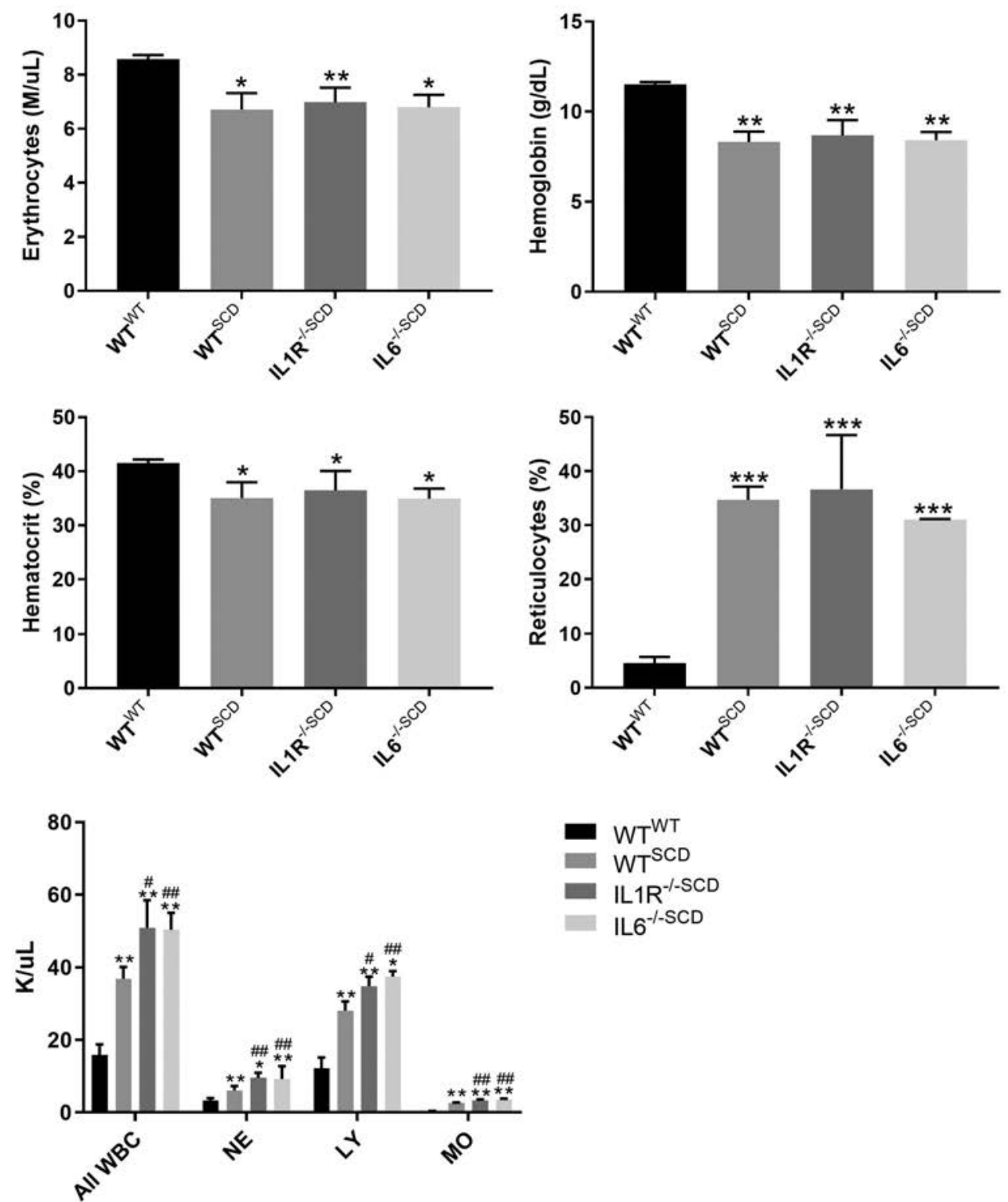

Figure 1. Blood parameter analysis at 15 weeks post-bone marrow transplantation. Circulating erythrocytes (A), hemoglobin (B), hematocrit (C), reticulocytes (D), and leukocytes $(\mathrm{E})$ of $\mathrm{Wt}, \mathrm{W} T^{\mathrm{bmt}}, \mathrm{Wt}, \mathrm{SCD}{ }^{\mathrm{bmt}}, \mathrm{IL} 1 R^{-}, \mathrm{SCD}^{\mathrm{bmt}}$ and $I L 6^{-1}, \mathrm{SCD}^{\mathrm{bmt}}$ mice (mean \pm standard deviation). Total WBC: total white blood cells; $\mathrm{NE}$ : neutrophils; LY: lymphocytes; MO: monocytes, $* P=<0.05, * * P<0.01, * * * P<0.005$ as determined by ANOVA. In Figure $1 \mathrm{E}$, asterisks indicates significance to $W t$, WT ${ }^{\mathrm{bmt}}$ and pound signs indicate significance to $W t, S C D^{\text {bmt }}$. 
Results from this study support a critical role of nonhematopoietic IL-1R signaling in mediating acute brain tissue damage in SCD mice in to the setting of ischemic stroke. This effect was associated with IL-1R-mediated regulation of endothelial adhesive properties. Signaling via the endothelial IL-1R leads to upregulation of endothelial adhesion molecules with resultant increases in leukocyteendothelial interactions and tissue leukocyte infiltration. ${ }^{40}$ This signaling pathway involves enhanced NFKB signaling. ${ }^{40}$ Enhanced endothelial expression of adhesion molecules is detrimental in SCD, promoting vascular occlu- sions and pain crises. ${ }^{52}$ Regulation of endothelial IL-1R responses to IL-1 $\beta$ has also been shown to occur indirectly by leukocyte interactions with selectins. For example, mice with leukocyte deficiency of p-selectin glycoprotein ligand-1 (Psgl-1) are resistant to IL-1 $\beta$-mediated stimulation of endothelial adhesion molecule expression and show reduced leukocyte-endothelial interactions. ${ }^{40}$ This is potentially relevant to SCD as an antibody to p-selectin, crizanlizumab, has been shown in human clinical trials to reduce the frequency of vaso-occlusive events. ${ }^{53}$ Preclincal studies have also shown that SCD mice treated with an
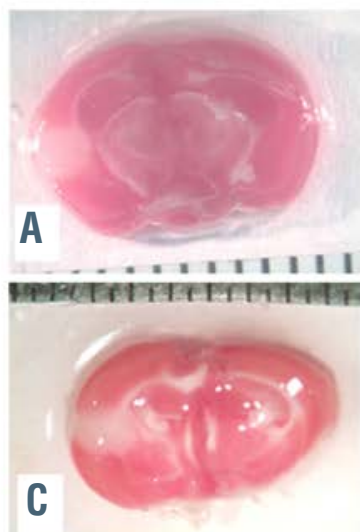
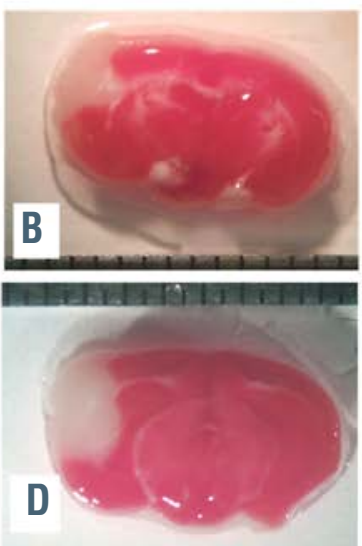

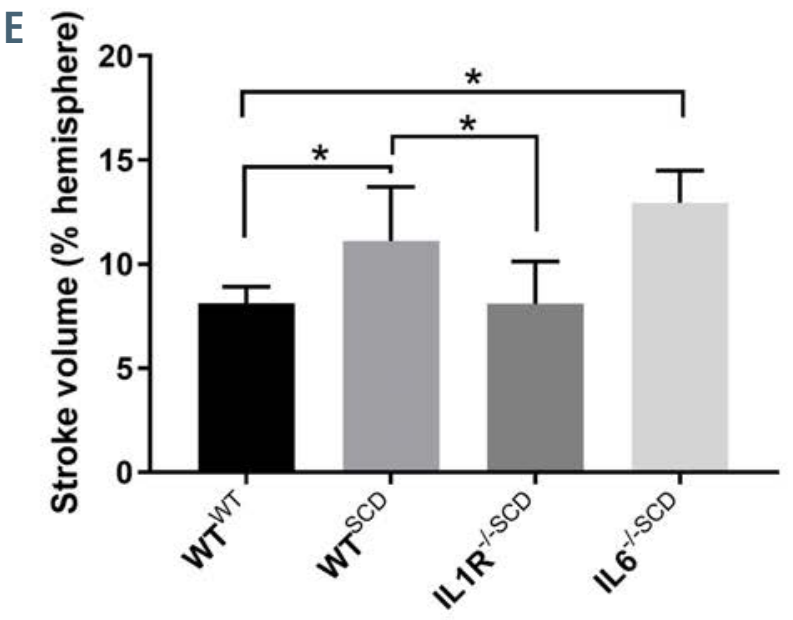

Figure 2. Stroke area following middle cerebral artery occlusion. Representative brain sections stained with $4 \% 2,3,5$-triphenyltetrazolium chloride (TTC) to assess stroke size (in white) of (A) Wt, $\mathrm{WT}^{\mathrm{bmt}}$, (B) Wt, SCD ${ }^{\mathrm{bmt}}$ (C) $I L 1 R^{-1}, \mathrm{SCD}^{\mathrm{bmt}}$ mice, and (D) $/ L 6^{-/}, \mathrm{SCD}^{\mathrm{bmt}}$ mice. (E) Quantification of stroke volume (mean \pm standard deviation). The brain sections were imaged with a Nikon SMZ-2T microscope and Spot Idea camera model 29.2-13MP using at Nikon 0.45x TV lens and Spot 5.1 software. $\star P<0.05$ as determined by ANOVA.
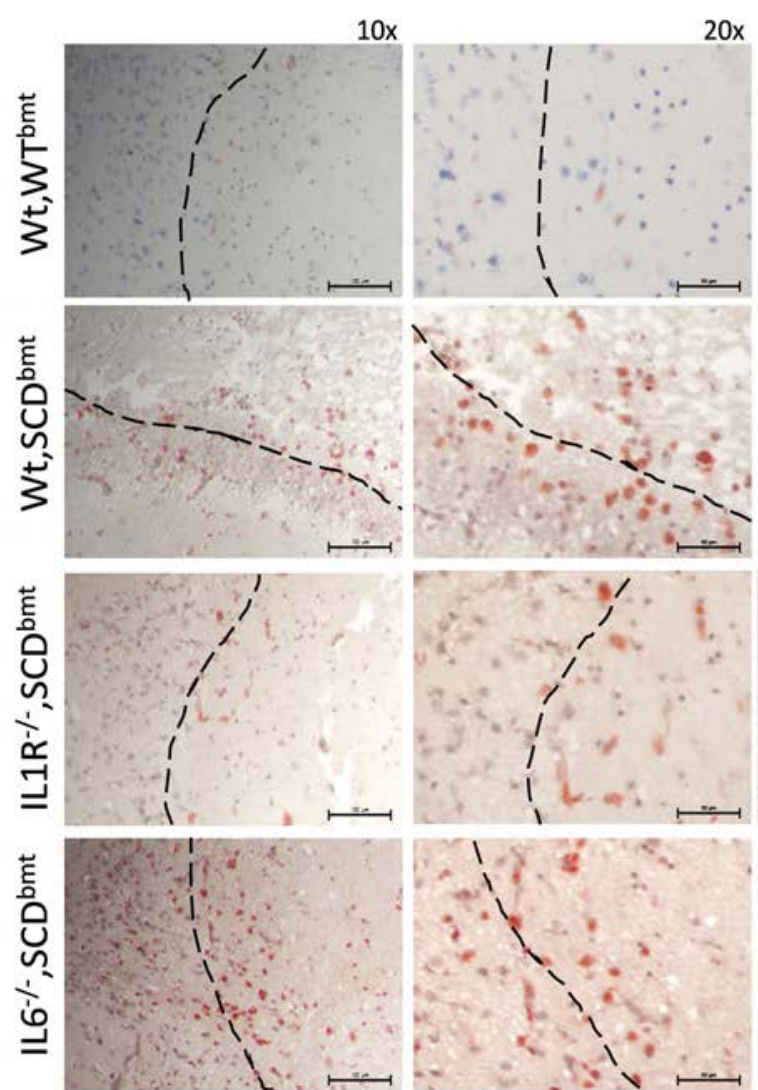

Contralateral, $10 x$

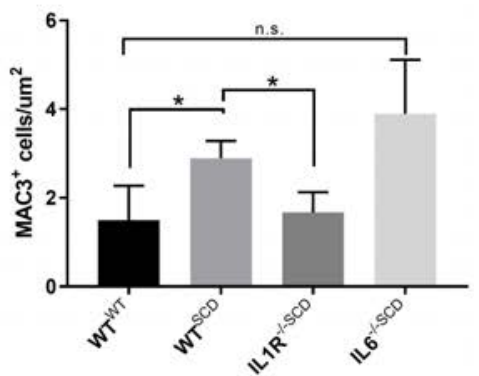

Figure 3. Post-stroke macrophage infiltration. Representative images of MAC3-positive cells in the peri-infact area of $W t, W T^{\mathrm{bmt}}$, $W t, \mathrm{SCD}^{\mathrm{bmt}}, I L 1 R^{-/}, \mathrm{SCD}^{\mathrm{bmt}}$ and $I L 6^{-/}, \mathrm{SCD}^{\mathrm{bmt}}$ mouse brains, and quantification (mean \pm standard deviation). A Nikon SE upright microscope and a Nikon DS-Fi3 camera was used to capture 10x and 20x images of ipsilateral brain and 10x images of contralateral brain. Dotted line denotes transition between infarcted area and heathy tissue. $\star P<0.05$ as determined by ANOVA. 

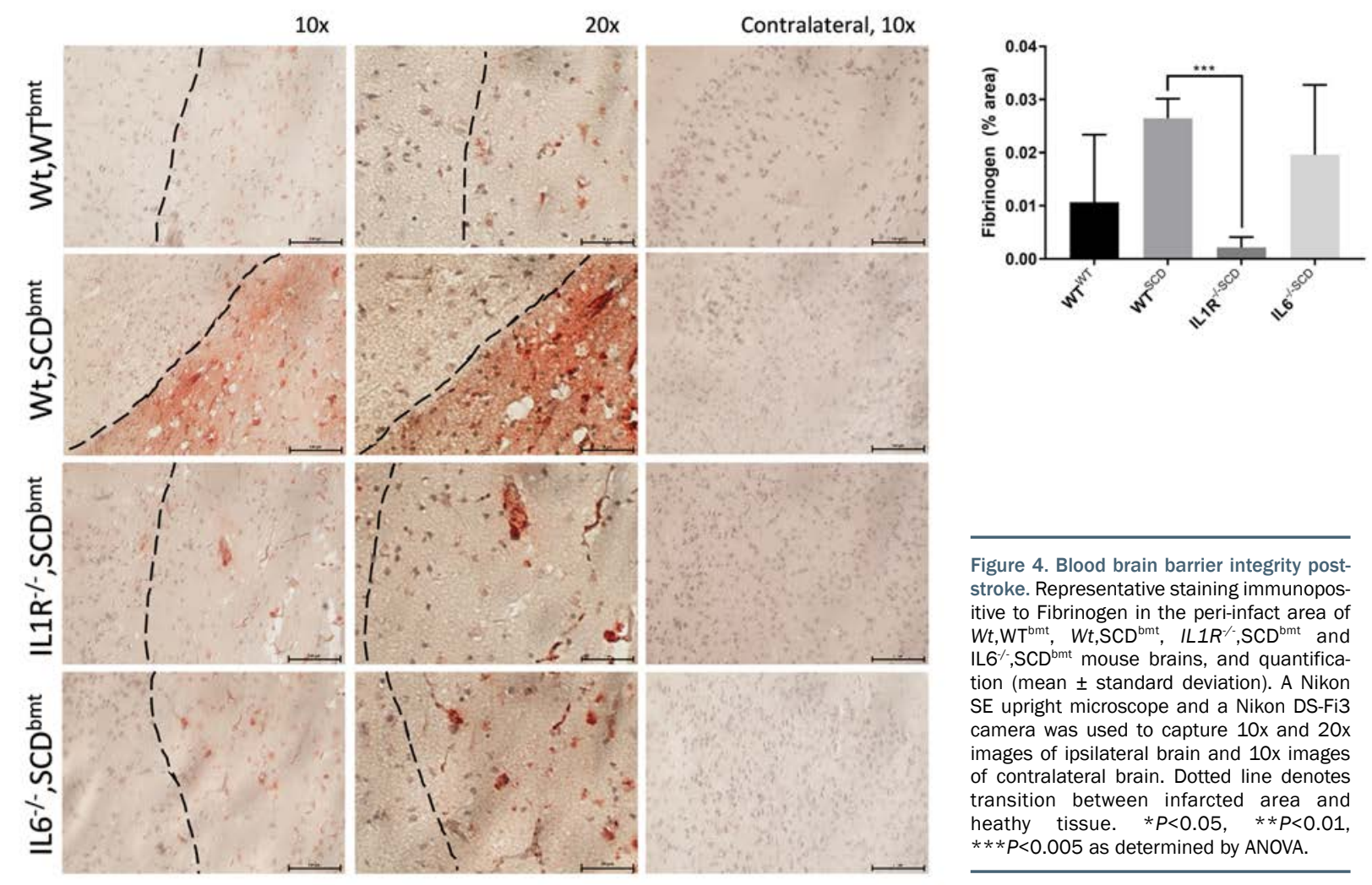

Figure 4. Blood brain barrier integrity poststroke. Representative staining immunopositive to Fibrinogen in the peri-infact area of $W t, \mathrm{WT}^{\mathrm{bmt}}, W t, \mathrm{SCD}^{\mathrm{bmt}}, \quad \mathrm{ILIR}^{-/}, \mathrm{SCD}^{\mathrm{bmt}}$ and $\mathrm{IL} 6^{-/}, \mathrm{SCD}^{\text {bmt }}$ mouse brains, and quantification (mean \pm standard deviation). A Nikon SE upright microscope and a Nikon DS-Fi3 camera was used to capture $10 x$ and $20 x$ images of ipsilateral brain and 10x images of contralateral brain. Dotted line denotes transition between infarcted area and heathy tissue. $\quad * P<0.05, \quad * * P<0.01$, $* * * P<0.005$ as determined by ANOVA.

A

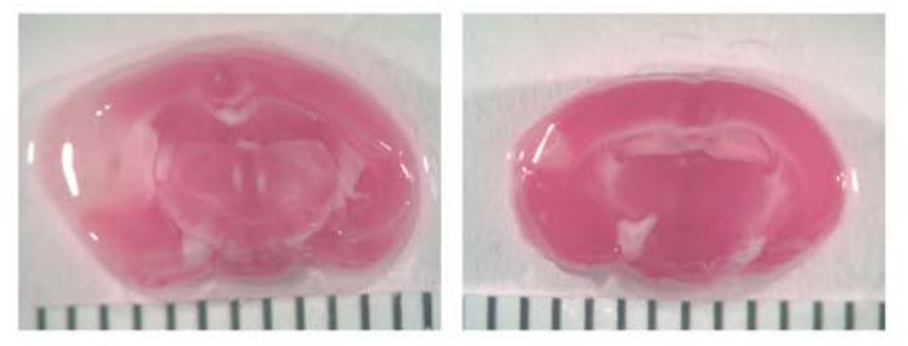

C

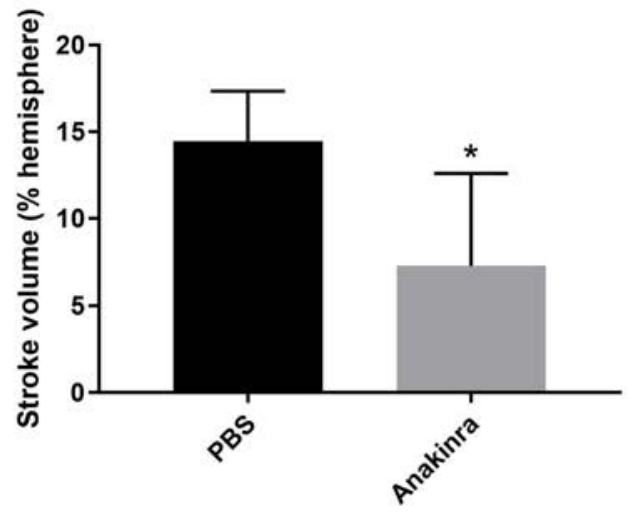

Figure 5. Infarct area in response to anakinra. Representative brain sections stained with $4 \%$ 2,3,5-triphenyltetrazolium chloride (TTC) in $W t$,SCD ${ }^{\text {bmt }}$ given one intraperitoneal injection of phosphate buffered saline (PBS) (A) or anakinra (B) immediately post-stroke induction, and quantification of stroke volume (mean \pm standard deviation) (C). The brain sections were imaged with a Nikon SMZ-2T microscope and Spot Idea camera model 29.2-13MP using at Nikon 0.45x TV lens and Spot 5.1 software. ${ }^{*} P<0.05$ as determined by student's $t$-test.

antibody to Psgl-1 displayed reduced leukocyte-endothelial interactions and reduced levels of circulating selectins. ${ }^{54}$ Circulating monocytes express Psgl-1 and use this receptor to engage E-selectin when undergoing extravasion from the vasculature to the damaged tissue..$^{55}$ In agreement with the known role of IL-1 $\beta$ in endothelial activation, ${ }^{4,54} I L 1 R^{-/}, S_{C D}{ }^{\text {bmt }}$ mice had lower circulating levels of sEsel post-stroke than $W t, \mathrm{SCD}^{\mathrm{bmt}}$ or $I L 6^{-1-}, \mathrm{SCD}^{\mathrm{bmt}}$ mice. The lower sEsel concentrations of $I L 1 R^{-/-}, \mathrm{SCD}^{\mathrm{bmt}}$ mice correlated with decreased MAC3-positive macrophages present in the peri-infarct area. A similar decrease in MAC3-positive cells was also attained with post-stroke administration of anakinra. ICAM-1 may also contribute to the leukocyte infiltration as immuno-stain- ing for ICAM-1 was also reduced in $I L 1 R^{-/-}, S_{C D}{ }^{\text {bmt }}$ mice compared to $W t, \mathrm{SCD}^{\mathrm{bmt}}$ mice in the peri-infarct region. This is consistent with a previous in vitro study in which ICAM-1 was upregulated on endothelial cells following exposure to sickled erythrocytes and was further increased in the presence of IL-1 $\beta .^{56}$

IL- $1 \beta$ has also been shown to reduce $\mathrm{BBB}$ integrity. ${ }^{36} \mathrm{~A}$ decrease in infarct-associated fibrin(ogen) immunostaining, was observed to be significantly decreased in $I L 1 R^{-/}, S_{C D}{ }^{\text {bmt }}$ mice relative to both $W_{t}, S_{C D}{ }^{\text {bmt }}$ and $I L 6^{-/}, \mathrm{SCD}^{\mathrm{bmt}}$ mice, suggesting less $\mathrm{BBB}$ disruption. As disruption of the $\mathrm{BBB}$ can lead to a greater influx of leukocytes ${ }^{57}$ inhibition of IL-1 $\beta$-mediated actions on endothelial cells may reduce leukocyte accumulation by both 

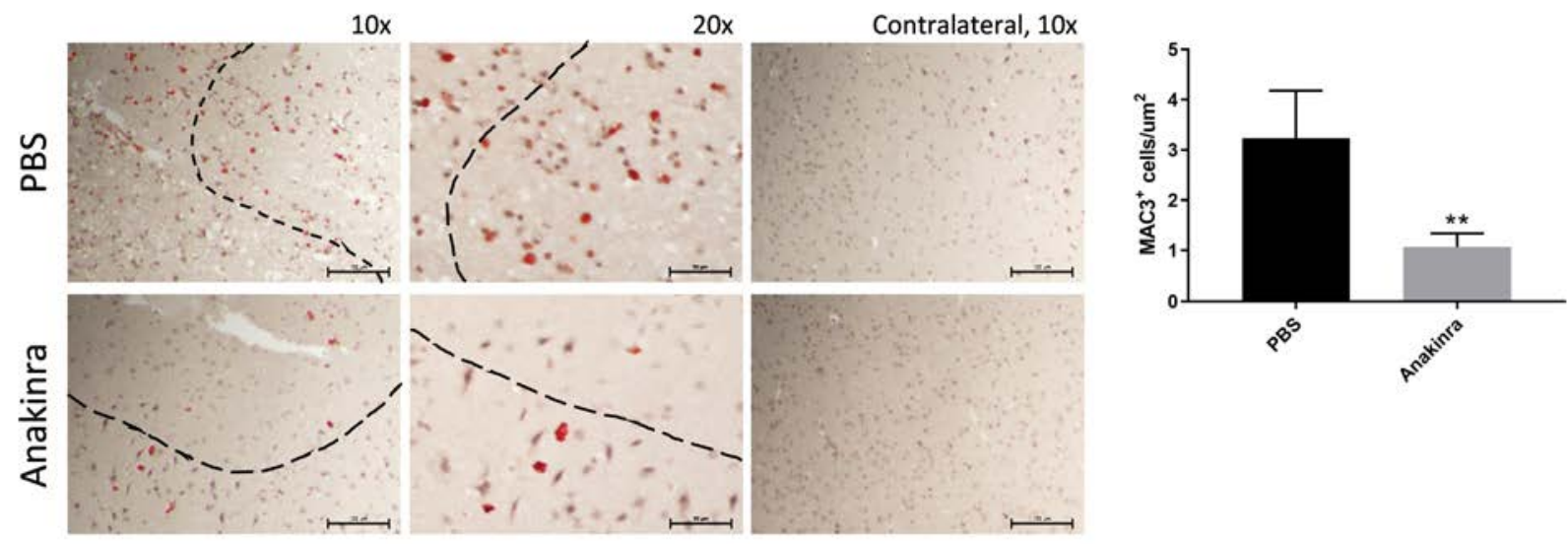

Figure 6. Post-stroke macrophage infiltration in response to anakinra. Representative staining immunopositive to MAC3 in the peri-infact area of $W t$,SCD ${ }^{\text {bmt }}$ given one intraperitoneal injection of phosphate buffered saline (PBS) or anakinra immediately post-stroke induction, and quantification of MAC3-positive cells (mean \pm standard deviation). A Nikon SE upright microscope and a Nikon DS-Fi3 camera was used to capture 10x and 20x images of ipsilateral brain and 10x images of contralateral brain. Dotted line denotes transition between infarcted area and heathy tissue. ${ }^{*} P<0.01$ as determined by student's $t$-test.

decreasing adhesion molecules such as E-selectin and ICAM-1, ${ }^{56}$ and also by preservation of BBB integrity. Although some studies have shown BBB integrity may be preserved by the action of macrophages, ${ }^{35}$ this study demonstrated that macrophages recruited acutely through IL-1R pathways may be deleterious. Long term human studies targeting IL-1 $\beta$ in SCD will be informative. A clinical study with the IL- $1 \beta$ antagonist, canakinumab, is currently underway to determine safety and efficacy of IL-1 $\beta$ inhibition in SCD patients (clincialtrials gov. Identifier: NCT02961218).

The beneficial effects of IL-1R inhibition observed in this study are independent of non-hematopoietic IL-6. In response to ischemia, neurons and other cell types in the brain produce IL- $6,{ }^{58,59}$ and circulating IL- 6 concentrations have been positively associated both with stroke size in patients, ${ }^{60}$ and with worsening outcomes within 48 hours post-stroke. ${ }^{61}$ While IL-6 may adversely affect stroke acutely. ${ }^{23,59}$ IL- 6 may show beneficial effects towards resolution of stroke damage. ${ }^{62}$ The assessment of stroke volume 72 hours after stroke induction in this study may have been too early to observe the full effects of IL-6 towards stroke repair. However, the failure of $I L-6^{-1-}, \mathrm{SCD}^{\text {bmt }}$ mice to phenocopy $I L 1 R^{-/-}, \mathrm{SCD}^{\mathrm{bmt}}$ mice in relation to stroke size illustrates the lack of dependence on the downstream induction of IL- 6 toward the acute detrimental action of IL-1R signaling.

While chronic treatment of SCD patients with anticytokine therapies may increase susceptibility to infections, short term treatment could be administered to patients presenting with acute complications. Remarkably, the IL-1R antagonist, anakinra, was beneficial even when administered following onset of MCA occlusion. These findings suggest that targeting the IL-1R may be beneficial in SCD patients presenting with stroke or other vascular complications.

Limitations of this work include the use of BMT to generate chimeric mice. It is possible the irradiation procedure used to ablate the bone marrow could have affected the vascular phenotypes, however, this strategy has been widely employed and greatly facilitates the generation of chimeric SCD mice. ${ }^{63-65}$ It is also possible that other beneficial effects of chimeric IL-1R deficiency in this model are at play. Although there were no differences in anemia between different recipient transgenic mice receiving sickle cell marrow, we cannot rule out differences in engraftment related to recipient IL-1R status. Future experiments with mice generated by crossbreedings to produce complete and tissue-specific gene deletions will be useful to confirm and expand these studies. The stroke model used in this study is induced by MCA thrombotic occlusion. A more relevant model would include spontaneous stroke due to vasoocclusion triggered by sickled erythrocytes. However, well validated models of spontaneous stroke are not available in SCD mice to our knowledge. Additionally, we cannot rule out differences in blood flow following MCA occlusion due to difference in IL-1R signaling. These studies would require a time course analysis after stroke induction in addition to laser doppler imaging. While there is no standard drug for treatment of acute stroke associated with sickle cell disease, future experiments comparing anakinra with tissue plasminogen activator or emergent blood transfusion would be interesting. Finally, longer periods between stroke induction and stroke volume measurement may be informative.

In conclusion, non-hematopoietic deficiency of the IL- $1 \mathrm{R}$ is sufficient to reduce stroke size in SCD. Therapies targeting this pathway may be beneficial towards the treatment of stroke and possibly other complications of SCD.

\section{Disclosures}

No conflicts of interest to disclose..

\section{Contributions}

DTE contributed to the conception and experimental design of this work; JV,JW, JM and CG contributed to the acquisition of data; JV and JM were responsible for data analysis; DTE and $J V$ contributed to the interpretation of the data, drafting and revision of the manuscript; DTE approved the final version of the work and agrees to be accountable for aspects of the work.

\section{Funding}

This work was supported by the National Institutes of Health (T32-HL007853 to JV. and a VA Merit Award (BX002776 to DTE). 


\section{References}

1. Fitzhugh $C D$, Lauder $N$, Jonassaint JC, et al. Cardiopulmonary complications leading to premature deaths in adult patients with sickle cell disease. Am J Hematol. 2010; 85(1):36-40.

2. Ohene-Frempong K, Weiner SJ, Sleeper LA, et al. Cerebrovascular accidents in sickle cell disease: rates and risk factors. Blood. 1998;91(1):288-294.

3. Strouse JJ, Lanzkron S, Urrutia V. The epidemiology, evaluation and treatment of stroke in adults with sickle cell disease. Expert Rev Hematol. 2011;4(6):597-606.

4. Webb J, Kwiatkowski JL. Stroke in patients with sickle cell disease. Expert Rev Hematol. 2013;6(3):301-316.

5. Sumoza A, de Bisotti R, Sumoza D, Fairbanks V. Hydroxyurea (HU) for prevention of recurrent stroke in sickle cell anemia (SCA). Am J Hematol. 2002;71(3):161-165.

6. Ware RE, Mueller BU. The second century of sickle cell disease. Pediatr Blood Cancer. 2012;59(2):352.

7. Hasson C, Veling L, Rico J, Mhaskar R. The role of hydroxyurea to prevent silent stroke in sickle cell disease: systematic review and meta-analysis. Medicine (Baltimore). 2019;98(51):e18225

8. Teixeira RS, Terse-Ramos R, Ferreira TA, et al. Associations between endothelial dysfunction and clinical and laboratory parameters in children and adolescents with sickle cell anemia. PLoS One. 2017;12(9): e0184076.

9. Zhou Z, Yee DL, Guchhait P. Molecular link between intravascular hemolysis and vascular occlusion in sickle cell disease. Curr Vasc Pharmacol. 2012;10(6):756-761.

10. Conran N, Belcher JD. Inflammation in sickle cell disease. Clin Hemorheol Microcirc. 2018;68(2-3):263-299.

11. Kaul DK, Finnegan E, Barabino GA. Sickle red cell-endothelium interactions. Microcirculation. 2009:16(1):97-111.

12. Vilas-Boas W, Cerqueira BA, Zanette AM, Reis MG, Barral-Netto M, Goncalves MS. Arginase levels and their association with Th17-related cytokines, soluble adhesion molecules (sICAM-1 and sVCAM-1) and hemolysis markers among steady-state sickle cell anemia patients. Ann Hematol. 2010;89(9):877-882.

13. Zennadi R, Chien A, Xu K, Batchvarova M, Telen MJ. Sickle red cells induce adhesion of lymphocytes and monocytes to endothelium. Blood. 2008:112(8):3474-3483.

14. Pitanga TN, Oliveira RR, Zanette DL, et al. Sickle red cells as danger signals on proinflammatory gene expression, leukotriene B4 and interleukin-1 beta production in peripheral blood mononuclear cell. Cytokine. 2016;83:75-84.

15. Platt OS. Hydroxyurea for the treatment of sickle cell anemia. N Engl J Med. 2008; 358(13):1362-1369.

16. Steinberg MH, McCarthy WF, Castro O, et al. The risks and benefits of long-term use of hydroxyurea in sickle cell anemia: A 17.5 year follow-up. Am J Hematol. 2010; 85(6):403-408.

17. Dutra FF, Alves LS, Rodrigues D, et al. Hemolysis-induced lethality involves inflammasome activation by heme. Proc Natl Acad Sci U S A. 2014;111(39):E4110E4118.

18. Wun T, Cordoba M, Rangaswami A, Cheung AW, Paglieroni T. Activated monocytes and platelet-monocyte aggregates in patients with sickle cell disease. Clin Lab Haematol. 2002;24(2):81-88.

19. Singhal R, Chawla S, Rathore DK, et al. Development of pro-inflammatory phenotype in monocytes after engulfing $\mathrm{Hb}$-activated platelets in hemolytic disorders. Clin Immunol. 2017; 175:133-142

20. Kalliolias GD, Ivashkiv LB. Targeting cytokines in inflammatory diseases: focus on interleukin-1-mediated autoinflammation. F1000 Biol Rep. 2009;1:70.

21. Dinarello CA, Simon A, van der Meer JW. Treating inflammation by blocking interleukin-1 in a broad spectrum of diseases. Nat Rev Drug Discov. 2012;11(8):633-652.

22. Ridker PM, Everett BM, Thuren $T$, et al. Antiinflammatory therapy with canakinumab for atherosclerotic disease. $\mathrm{N}$ Engl J Med. 2017;377(12):1119-1131.

23. Huang CM, Tsai FJ, Wu JY, Wu MC. Interleukin-1beta and interleukin-1 receptor antagonist gene polymorphisms in rheumatoid arthritis Scand I Rheumatol. 2001;30(4):225-228.

24. Vicari P, Adegoke SA, Mazzotti DR, Cancado RD, Nogutti MA, Figueiredo MS. Interleukin-1beta and interleukin-6 gene polymorphisms are associated with maniestations of sickle cell anemia. Blood Cells Mol Dis. 2015;54(3):244-249.

25. Denes A, Pinteaux E, Rothwell NJ, Allan SM. Interleukin-1 and stroke: biomarker, harbinger of damage, and therapeutic target. Cerebrovasc Dis. 2011;32(6):517-527.

26. Sobowale OA, Parry-Jones AR, Smith CJ, Tyrrell PJ, Rothwell NJ, Allan SM. Interleukin-1 in stroke: from bench to bedside. Stroke. 2016:47(8):2160-2167.

27. McCann SK, Cramond F, Macleod MR, Sena ES. Systematic review and metaanalysis of the efficacy of interleukin-1 receptor antagonist in animal models of stroke: an update. Transl Stroke Res. 2016; 7(5):395-406

28. Parker LC, Luheshi GN, Rothwell NJ, Pinteaux E. IL-1 beta signalling in glial cells in wildtype and IL-1RI deficient mice. Br J Pharmacol. 2002;136(2):312-320

29. Thornton P, Pinteaux E, Allan SM, Rothwell NJ. Matrix metalloproteinase-9 and urokinase plasminogen activator mediate interleukin-1-induced neurotoxicity. Mol Cell Neurosci. 2008:37(1):135-142.

30. Giles JA, Greenhalgh AD, Denes A, et al. Interleukin-1 and platelets as key drivers of cerebrovascular inflammation. Immunology. 2011;135:154.

31. Ching S, Zhang $\mathrm{H}$, Belevych $\mathrm{N}$, et al. Endothelial-specific knockdown of interleukin-1 (IL-1) type 1 receptor differentially alters CNS responses to IL-1 depending on its route of administration. I Neurosci. 2007;27(39):10476-10486.

32. Bolton SJ, Anthony DC, Perry VH. Loss of the tight junction proteins occludin and zonula occludens-1 from cerebral vascular endothelium during neutrophil-induced blood-brain barrier breakdown in vivo. Neuroscience. 1998;86(4):1245-1257.

33. Basu A, Krady JK, Levison SW. Interleukin1: a master regulator of neuroinflammation. J Neurosci Res. 2004;78(2):151-156.

34. Allen C, Thornton P, Denes A, et al. Neutrophil cerebrovascular transmigration triggers rapid neurotoxicity through release of proteases associated with decondensed DNA. J Immunol. 2012;189(1):381-392.

35. Li Y, Zhu ZY, Huang TT, et al. The peripheral immune response after stroke-A double edge sword for blood-brain barrier integrity. CNS Neurosci Ther. 2018; 24(12):
1115-1128.

36. Fahey E, Doyle SL. IL-1 Family cytokine regulation of vascular permeability and angiogenesis. Front Immunol. 2019; 10:1426.

37. Paszty C, Brion CM, Manci E, et al. Transgenic knockout mice with exclusively human sickle hemoglobin and sickle cell disease. Science. 1997;278(5339):876-878.

38. Ryan TM, Ciavatta DJ, Townes TM Knockout-transgenic mouse model of sick le cell disease. Science. 1997;278(5339):873876.

39. Wu LC, Sun CW, Ryan TM, Pawlik KM, Ren J, Townes TM. Correction of sickle cell disease by homologous recombination in embryonic stem cells. Blood. 2006; 108(4):1183-1188

40. Russo HM, Wickenheiser KJ, Luo W, et al P-selectin glycoprotein ligand-1 regulates adhesive properties of the endothelium and leukocyte trafficking into adipose tissue. Circ Res. 2010;107(3):388-397.

41. Wang J, Tran J, Wang $\mathrm{H}$, et al. mTOR Inhibition improves anaemia and reduces organ damage in a murine model of sickle cell disease. Br J Haematol. 2016; 174(3):461-469.

42. Luo W, Su EJ, Wang J, et al. Increased stroke size following MCA occlusion in a mouse model of sickle cell disease. Blood. 2014; 23(12):1965-1967.

43. Campbell AD, Cui S, Shi L, et al. Forced TR2/TR4 expression in sickle cell disease mice confers enhanced fetal hemoglobin synthesis and alleviated disease phenotypes. Proc Natl Acad Sci U S A. 2011; 108(46):18808-18813.

44. Ching S, He L, Lai W, Quan N. IL-1 type I receptor plays a key role in mediating the recruitment of leukocytes into the central nervous system. Brain Behav Immun. 2005;19(2):127-137.

45. Akassoglou K, Strickland S. Nervous system pathology: the fibrin perspective. Bio Chem. 2002;383(1):37-45.

46. Adams RA, Passino M, Sachs BD, Nuriel T, Akassoglou K. Fibrin mechanisms and functions in nervous system pathology. Mol Interv. 2004:4(3):163-176.

47. Petersen MA, Ryu JK, Akassoglou K. Fibrinogen in neurological diseases: mechanisms, imaging and therapeutics. Nat Rev Neurosci. 2018;19(5):283-301

48. Bunn HF. Pathogenesis and treatment of sickle cell disease. N Engl J Med. 1997; 337(11):762-769.

49. Steinberg MH. Predicting clinical severity in sickle cell anaemia. Br J Haematol. 2005; 129(4):465-481.

50. Steinberg MH, Rodgers GP. Pathophysiology of sickle cell disease: role of cellular and genetic modifiers. Semin Hematol. 2001;38(4):299-306.

51. Su EJ, Geyer M, Wahl M, et al. The thrombomodulin analog Solulin promotes reperfusion and reduces infarct volume in thrombotic stroke model J Thromb Haemost. 2011;9(6):1174-1182

52. Telen MJ. Role of adhesion molecules and vascular endothelium in the pathogenesis of sickle cell disease. Hematology Am Soc Hematol Educ Program. 2007:84-90.

53. Ataga KI, Kutlar A, Kanter J, et al. Crizanlizumab for the prevention of pain crises in sickle cell disease. N Engl J Med. 2017:376(5):429-439.

54. Luo W, Campbell A, Wang H, et al. Pselectin glycoprotein ligand-1 inhibition blocks increased leukocyte-endothelia interactions associated with sickle cell dis- 
ease in mice. Blood. 2012:120(18):38623864.

55. An G, Wang H, Tang R, et al. P-selectin glycoprotein ligand-1 is highly expressed on Ly-6Chi monocytes and a major determinant for Ly-6Chi monocyte recruitment to sites of atherosclerosis in mice. Circulation. 2008;117(25):3227-3237.

56. Shiu YT, Udden MM, McIntire LV. Perfusion with sickle erythrocytes up-regulates ICAM-1 and VCAM-1 gene expression in cultured human endothelial cells. Blood. 2000;95(10):3232-3241.

57. Obermeier B, Daneman R, Ransohoff RM. Development, maintenance and disruption of the blood-brain barrier. Nat Med. 2013; 19(12):1584-1596.

58. Schwaninger $M$, Neher M, Viegas E, Schneider A, Spranger M. Stimulation of interleukin-6 secretion and gene transcrip tion in primary astrocytes by adenosine. Neurochem. 1997;69(3):1145-1150

59. Suzuki S, Tanaka K, Suzuki N. Ambivalent aspects of interleukin-6 in cerebral ischemia: inflammatory versus neurotrophic aspects. I Cereb Blood Flow Metab. 2009;29(3):464-479.

60. Hotter B, Hoffmann S, Ulm L, Meisel C, Fiebach JB, Meisel A. IL-6 Plasma levels correlate with cerebral perfusion deficits and infarct sizes in stroke patients without associated infections. Front Neurol. 2019, 10:83.

61. Vila N, Reverter JC, Yague J, Chamorro A Interaction between interleukin-6 and the natural anticoagulant system in acute stroke. I Interferon Cytokine Res. 2000 20(3):325-329.
62. Doll DN, Barr TL, Simpkins JW. Cytokines: their role in stroke and potential use as biomarkers and therapeutic targets. Aging Dis. 2014;5(5):294-306

63. Wood KC, Hebbel RP, Granger DN Endothelial cell NADPH oxidase mediates the cerebral microvascular dysfunction in sickle cell transgenic mice. FASEB J 2005;19(8):989-991.

64. Ghosh S, Adisa OA, Chappa P, et al Extracellular hemin crisis triggers acute chest syndrome in sickle mice. I Clin Invest. 2013;123(11):4809-4820.

65. Chang KH, Nayak RC, Roy S, et al. Vasculopathy-associated hyperangiotensinemia mobilizes haematopoietic stem cells/progenitors through endothelial AT(2)R and cytoskeletal dysregulation. Nat Commun. 2015;6:5914. 